\title{
Adaptive Neuro-fuzzy Inference System based Earth Surface Features Classification System
}

\author{
Temitope M. Ogungboyega \\ Electrical/Electronic \& Computer \\ Engineering \\ University of Uyo, Nigeria
}

\author{
Kingsley M. Udofia \\ Electrical/Electronic \& Computer \\ Engineering \\ University of Uyo, Nigeria
}

\author{
Chidinma N. Kalu \\ Electrical/Electronic \& Computer \\ Engineering \\ University of Uyo, Nigeria
}

\begin{abstract}
This paper aimed at developing a model that will aid the process of identifying and extracting earth surface features from satellite images using adaptive neuro-fuzzy inference system. Conventional methods of classifying earth features (Normalized Difference Vegetation Index, NDVI, and Normalized Difference Water Index, NDWI) were first used to generate the data for the training of the ANFIS model using the three bands in Landsat 8 (band 2: Blue, band 4: Red and band 5: NIR). The performance of the developed ANFIS model was validated using four different satellite images and the results compared with the conventional classification methods. An accuracy level of $98.66-99.88 \%$ with a RMSE of $0.0218-0.0506$ were obtained.
\end{abstract}

\section{General Terms}

Satellite images, image identification and classification, earth surface features.

\section{Keywords}

Spectral signature, Normalized Difference Vegetation Index (NDVI), Normalized Difference Water Index (NDWI), Adaptive Neuro-Fuzzy Inference System (ANFIS), NearInfrared (NIR).

\section{INTRODUCTION}

Water, soil and vegetation are essential components of ecosystem for the sustainability of life on earth. They balance ecosystem and maintain climate variation, carbon cycling, etc. The identification of water bodies, soil and vegetation region is an essential process in science and engineering research. The identification of soil can be useful in various ways, such as estimation of water areas, demarcation of flooded regions, wetland inventories, change detection, and so on. Its availability helps in the estimation of agricultural land irrigation, productivity, hydropower energy, and many others [1]. Soil surveys are the main information source for sustainable agriculture and land use management. Soil survey mapping units are defined by the soil properties that affect management practices, such as drainage, erosion control, tillage and nutrition, and they involve the whole soil profile [2]. While, soil degradation caused by combined social and climate factors is now on the increase, its economic impact has affected many regional developments as it touched the national and international financial budgeting[3][4]. As a result, poor soil quality, declined soil fertility and environmental quality have capitulated decrease in food production and economic profits in the entire African region [5].
Remote sensing and photogrammetric techniques provide spatially explicit, digital data representations of the earth's surface that can be combined with digitized paper maps in GIS to allow efficient characterization and analysis of vast amounts of data. Satellite remote sensing, in conjunction with GIS, has proved to be an extremely useful tool for natural resource management. Integration of remote sensing within a GIS database can decrease the cost, reduce the time and increase the detailed information gathered for soil survey [6].

The use of digital image processing for soil survey and mapping was initiated with the establishment of National Remote Sensing Agency and Regional Remote Sensing Service Centers. The initial works carried out by some researchers demonstrated the potential of digital image processing techniques for soil survey [7] [8] [9]. The introduction of GIS promoted interdisciplinary studies, both within the natural, environmental, social and economic sciences. Its applications have expanded rapidly in parallel with advances in remote sensing and provides infrastructure for the examination of complex spatial problems in new and exciting ways [10]. GIS proved to be an effective tool in handling spatial data available at different scales, voluminous point data to perform integrated analysis of data on various resources of any region and to arrive at optimum solutions for various problems.

The main objective of the project is to develop a model that aids the process of identifying and extracting soil, vegetation and water bodies from satellite images using adaptive neurofuzzy inference system (ANFIS). This will be achieved by developing an algorithm that delineates soil, vegetation and water bodies using spectral signature from satellite images, obtaining satellite image for various bands from Advance Space Technology Applications Laboratory, University of Uyo, developing an ANFIS based model for earth surface features classification, implementing and evaluating results.

\section{LITERATURE REVIEW}

\subsection{Spectral Signature}

Spectral reflectance $[\rho(\lambda)]$ is the ratio of reflected energy to incident energy as a function of wavelength. It is responsible for the colour or tone in a photographic image of an object. Various materials of the earth's surface have different spectral reflectance characteristics. The values of the spectral reflectance of objects averaged over different, well-defined wavelength intervals comprise the spectral signature of the objects or features by which they can be distinguished. The spectral reflectance is dependent on wavelength, it has different values at different wavelengths for a given terrain 
feature and this value can be calculated using the formula in equation 1 .

$\rho(\lambda)=\left[\frac{\operatorname{ER}(\lambda)}{\operatorname{EI}(\lambda)}\right] * 100$

Where, $\rho(\lambda)=$ Spectral reflectance (reflectivity) at a particular wavelength, $\operatorname{ER}(\lambda)=$ Energy of wavelength reflected from object, EI $(\lambda)=$ Energy of wavelength incident upon the object.

The spectral characteristics of the three main earth surface features (water, soil and vegetation) are determined from their behavior in the spectral regions. These spectral regions are: Visible spectral region, near-infrared region and mid-infrared spectral region.

In the visible spectral region, vegetation generally has low reflectance and low transmittance. This is mainly due to plant pigments absorbing visible light. Plant pigment in leaves called chlorophyll strongly absorbs radiation in the red and blue wavelengths for photosynthesis but reflects green wavelength. Green light is not absorbed for photosynthesis and therefore most plants appear green. Water looks blue or blue green due to stronger reflectance at shorter wavelengths and darker if viewed at red or near-infrared wavelengths.

In the near-infrared spectral region, plants generally reflect radiation highly. This is mainly due to the high air cell interface area within leaves and high chlorophyll content [11] [12]. The reflectance of near-infrared radiation also varies depending upon the shape and orientation of plant leaves [13]. The majority of radiation incident on a soil surface is either reflected or absorbed and little is transmitted. The presence of moisture in soil decreases its reflectance.

In mid-infrared spectral region, pure water strongly absorbs radiation from the mid-infrared spectral region. Therefore, mid-infrared reflectance by plants has been shown to be directly related to leaf water content [14] [15] [16].

By measuring the energy that is reflected by targets on earth's surface over a variety of different wavelengths, a spectral signature for that object can be built. Comparing the response pattern of different features will help to distinguish between them, which may not be achieved if they are compared at only one wavelength. For example, water and vegetation reflect somewhat similarly in the visible wavelength but not in the infrared.

\subsection{Normalized Difference Vegetation Index}

Normalized Difference Vegetation Index (NDVI) is one of the methodologies for studying seasonal changes in vegetation through satellite images, this method applies to vegetation indices relating to the quantity of greenness [17]. The NDVI is a dimensionless index that has its values in the range of -1 to +1 , it measures the balance between energy received and energy emitted by objects on Earth. This index establishes a value for how green an area is, that is, the quantity of vegetation present in a given area and its state of health or vigor of growth. Basically, NDVI is a function of two bands; the red band and the near-infrared spectral band and it is calculated based on these bands as shown in equation 2 [18] [19].
$\mathrm{NDVI}=\frac{(N I R-R E D)}{(N I R+R E D)}$

Where NIR and RED are the amounts of light reflected by growing vegetation and registered by satellite sensor [20]. Green vegetation has high visible light absorption and high near infrared reflectance, which results in high, positive NDVI values. Dry vegetation, snow, water, clouds and soil absorb considerably more of NIR leading to lower NDVI values [21]. In practice, the values that are below 0.1 correspond to bodies of water and bare ground, while higher values are indicators of high photosynthetic activity linked to scrub land, temperate forest, rain forest and agricultural activity.

\subsection{Normalized Difference Water Index}

The Normalized Difference Water Index (NDWI) was first proposed by McFeeters in 1996 to detect surface waters in wetland environments and to allow for the measurement of surface water extent [22]. It is designed to maximize reflectance of water by using green wavelengths; minimize the low reflectance of NIR by water features; and also to take advantage of the high reflectance of NIR by vegetation and soil features. This index can be calculated using the formula in Equation (3).

$$
N D W I=\frac{(\text { Band } 2-\text { Band } 4)}{(\text { Band } 2+\text { Band } 4)}
$$

Where Band 2 is the top-of-atmosphere (TOA) green light reflectance and Band 4 is the TOA near-infrared (NIR) reflectance. NDWI of water features have positive values and as such they are more pronounced, while vegetation and soil usually have zero or negative values and therefore are suppressed [22].

\subsection{Adaptive Neuro-Fuzzy Inference System}

An adaptive network is a network structure consisting of nodes and directional links, the overall input-output behavior is determined by the values of a collection of modifiable parameters through which the nodes are connected [23]. The adaptive system uses a hybrid learning algorithm to identify parameters of Sugeno-type fuzzy inference systems. The main benefit of a hybrid approach is that it converges much faster, since it reduces the search space dimensions of the back propagation method used in neural networks [24]. A combination of the gradient descent algorithm and a least squares algorithm is used for training fuzzy inference system membership function to obtain an effective search for the optimal parameters [25]. The parameters to be optimized in ANFIS are the premise parameters. The network learns in two main phases, the forward phase and the backward phase (see Table 1). In the forward phase of the learning algorithm, consequent parameters identify the least squares estimate. In the backward phase, the error signals, which are the derivatives of the squared error with respect to each node output, propagate backward from the output layer to the input layer. In this backward pass, the premise parameters are updated by the gradient descent algorithm. Figure 1 shows the entire system architecture of an adaptive network which consists of five layers, namely fuzzy layer, product layer, normalized layer, de-fuzzy layer and total output layer. 


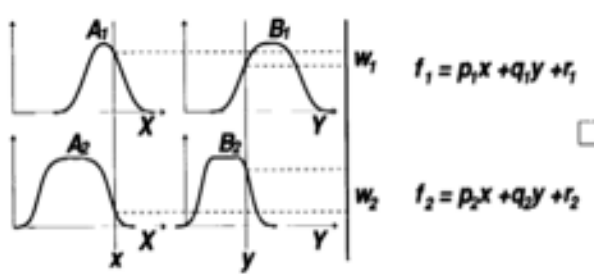

(a)

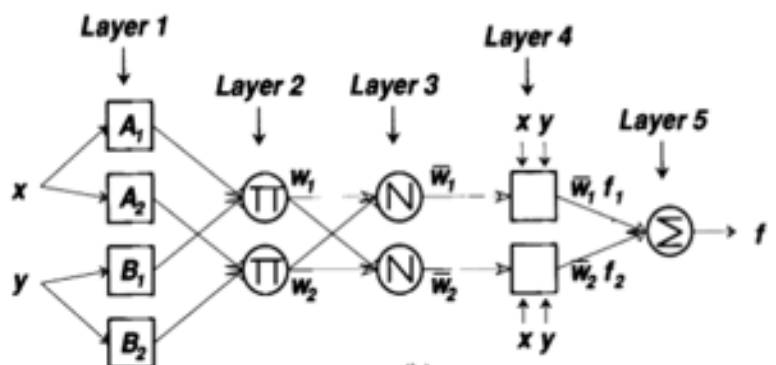

(b)

Fig 1: a) A two-input first-order Sugeno fuzzy model with two rules b) Equivalent ANFIS architecture

In Layer 1, the node $\mathrm{i}$ is a membership function i.e., triangle, trapezoidal, or gaussian, etc. For example, $\mu \mathrm{A} 1, \mu \mathrm{A} 2$ and $\mu \mathrm{B} 1, \mu \mathrm{B} 2$ are the membership functions of gaussian shape with two parameters center (c) and width $(\sigma)$ as shown in equation 4 . Layer 2 calculates the firing strength of a rule via product $\Pi$ operation using equation 5 . Layer 3 is normalized firing strength of a rule from previous layer (see equation 6). In Layer 4, each node represents consequent part of fuzzy rule. The linear coefficients of rule consequent are trainable as seen in equation 7.

$O_{1, i=\mu A_{i}}$ for $i=1,2$,or $O_{1, i}=\mu B_{i-2}$ for $i=3,4$

$O_{2, i}=\omega_{i}=\mu A_{i}(\mathrm{x}) \cdot \mu B_{i}(\mathrm{y}), i=1,2$

$O_{3, i}=\bar{\omega}_{i}=\frac{\omega_{i}}{\omega_{1}+\omega_{2}}, i=1,2$

$\mathrm{O}_{4, \mathrm{i}}=\bar{\omega}_{\mathrm{i}} \mathrm{f}_{\mathrm{i}}=. \bar{\omega}_{\mathrm{i}}\left\{\mathrm{p}_{\mathrm{x}}+\mathrm{q}_{\mathrm{i} \mathrm{y}}+\mathrm{r}_{\mathrm{i}}\right\}$

Where $\bar{\omega}_{i}$ is the normalized firing strength from layer 3 , and $\left\{p_{i}, q_{i}, r_{i}\right\}$ is the parameter set of this node which are all consequent parameters. Nodes in Layer 5 perform defuzzification of consequent part of rules by summing outputs of all the rules as shown in equation 8 [26].

Overall output $O_{5, i}=\sum_{i} \bar{\omega}_{i} f_{i}=\frac{\sum_{i} \omega_{i} f_{i}}{\sum_{i} \omega_{i}}$

Table 1. Two-pass ANFIS learning algorithm

\begin{tabular}{|c|c|c|}
\hline & Forward Pass & Backward Pass \\
\hline Premise Parameters & Fixed & Gradient descent \\
\hline $\begin{array}{c}\text { Consequent } \\
\text { Parameters }\end{array}$ & $\begin{array}{c}\text { Least Square } \\
\text { Estimation }\end{array}$ & Fixed \\
\hline Signals & Node Outputs & Error Signal \\
\hline
\end{tabular}

\section{METHODOLOGY}

This work entails first developing an algorithm that identifies and classifies earth surface into soil, vegetation and water bodies from satellite images. The algorithm uses three different bands from LANDSAT8 images for the classification. These bands are Red, Blue, and NIR. The classification system is modelled using adaptive neuro-fuzzy inference system (ANFIS). Figure 2 shows the block diagram of the procedure used. The study was conducted with information collection of Landsat8 satellite image at Klang, Selangor, between longitudes $101^{\circ} 16^{\prime}$ to $102^{\circ} 00^{\prime} \mathrm{E}$ and scope $3^{\circ} 05^{\prime}$ to $3^{\circ} 22^{\prime} \mathrm{N}$, procured from Advance Space Technology
Applications Laboratory University of Uyo. The multispectral bands Landsat 8 data contains visible and infrared wavelength.

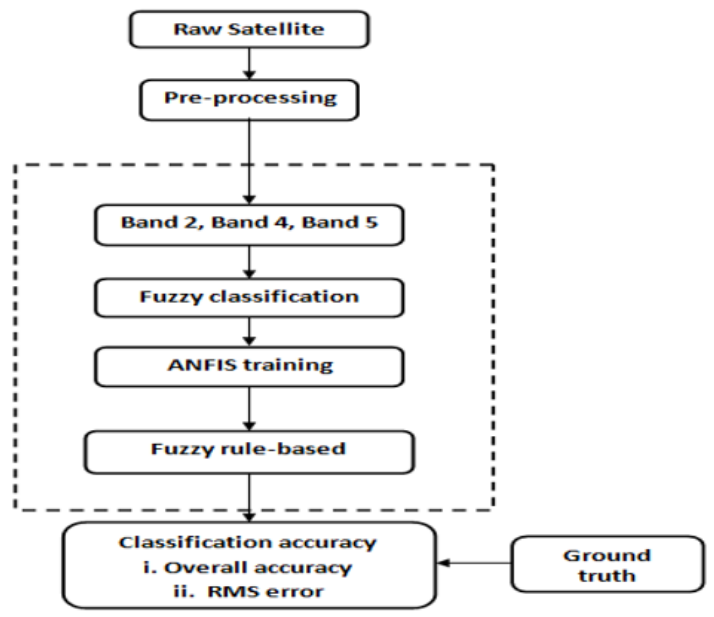

Fig 2: Block diagram of the methodology

In this work, two standard earth features classifcation methods were adopted in the generation of training data for the ANFIS model: Normalized Difference Vegetation Index (NDVI) and the Normalised Difference Water Index (NDWI). The following threshold values were used for the delineation the earth surface features:
i. Water: NDWI $>0$ and NDVI $<0.02$
ii. Soil: $0.02 \leq$ NDVI $<0.14$
iii. Vegetation: NDVI $\geq 0.14$

Figure 3 shows the developed ANFIS model. The membership functions of the three inputs are shown in Figure 4. For the training, the number of membership function used is three for each input, thus $27\left(3^{3}\right)$ rules were obtained. The ANFIS structure is as shown in Figure 5.

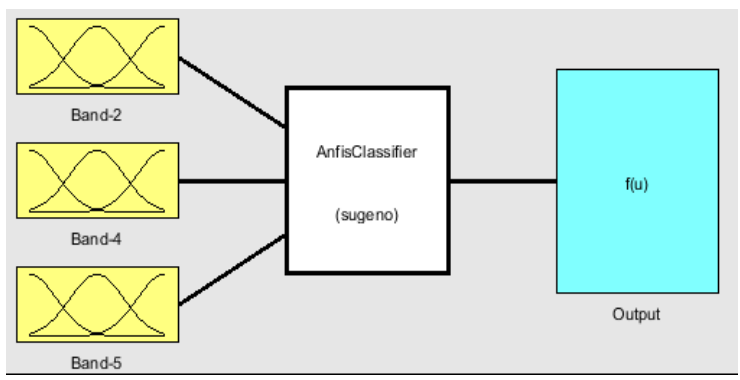

Fig 3: ANFIS model 


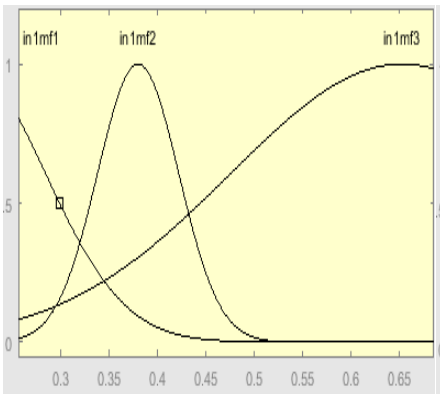

(a)

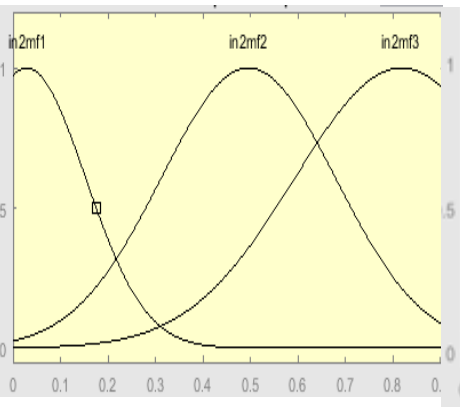

(b)

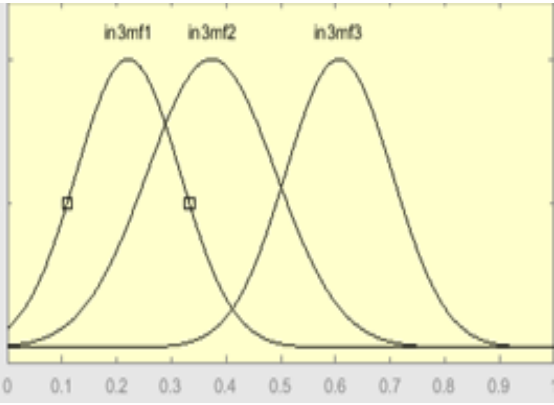

(c)

Fig 4: Membership function plot for input variables (a) band 2, (b) band 4, (c) band 5

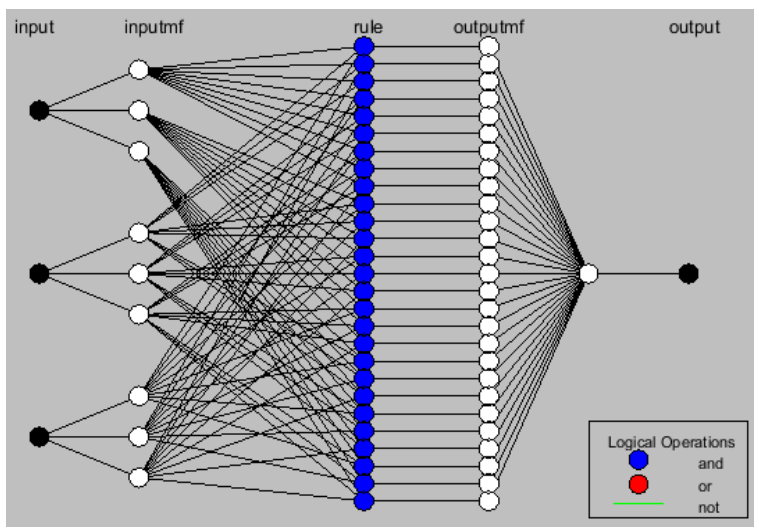

Fig 5: ANFIS Model structure

\section{RESULTS}

The developed ANFIS classifier model was validated with satellite image (Figure 6a) using MATLAB software. The result obtained (Figure 6c) was compared with the base data obtained from NDVI and NDWI (Figure 6b). Accuracy of
$99.07 \%, 99.86 \%$ and $99.21 \%$ were obtained for Bare land, Water and Vegetation respectively, while RMSE value was 0.0506 (see Table 2).

Table 2: Percentage coverage Area and accuracy for sample validation image

\begin{tabular}{|c|c|c|c|c|}
\hline $\begin{array}{c}\text { Earth } \\
\text { features }\end{array}$ & $\begin{array}{c}\text { NDVI } \\
\text { and } \\
\text { NDWI }\end{array}$ & ANFIS & Accuracy & RMSE \\
\cline { 1 - 4 } Bare Land & 20.4094 & 20.0966 & 99.0761 & \multirow{2}{*}{0.0506} \\
\cline { 1 - 4 } Water & 4.6856 & 4.7399 & 99.8565 & \\
\hline Vegetation & 74.9049 & 75.1635 & 99.2182 & \\
\hline
\end{tabular}

The developed ANFIS model was then applied to four sample satellite images and the results of the classification were compared to the base data obtained using NDVI and NDWI as presented in Figures $7-10$ and Table 3.

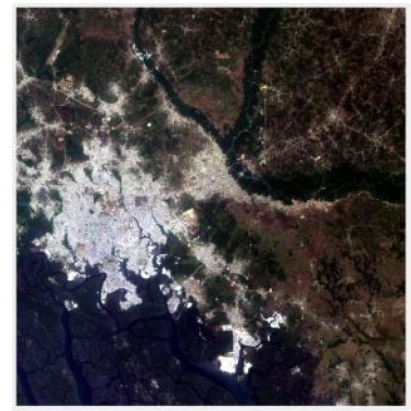

(a)

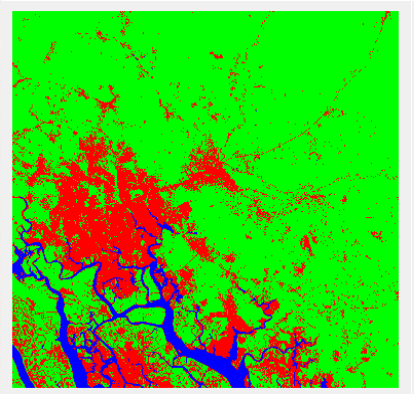

(b)

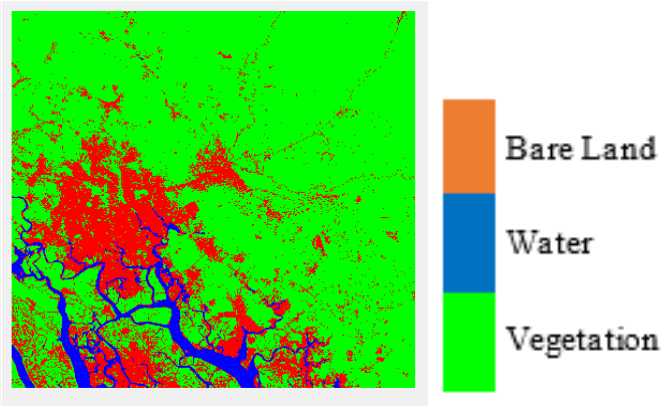

(c)

Fig 6: (a) Sample validation image (b) NDVI and NDWI classification (b) ANFIS model classification

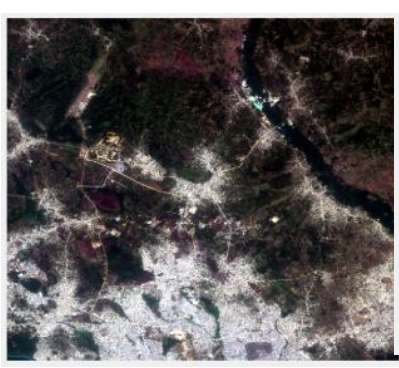

(a)

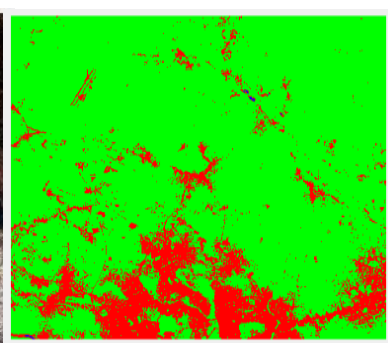

(b)

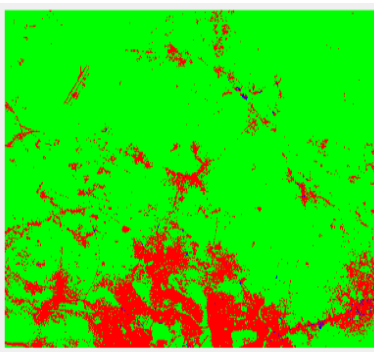

(c)

Fig 7: (a) Testing image 1 (b) NDVI and NDWI classification (b) ANFIS model classification 


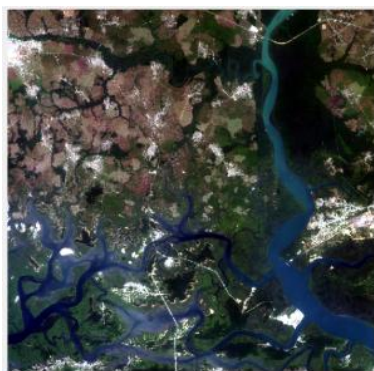

(a)

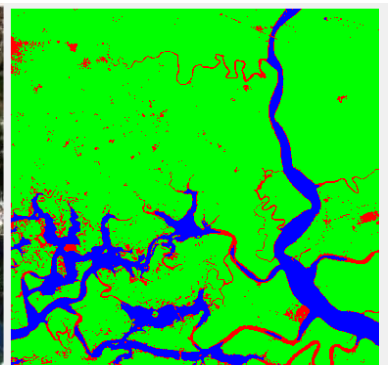

(b)

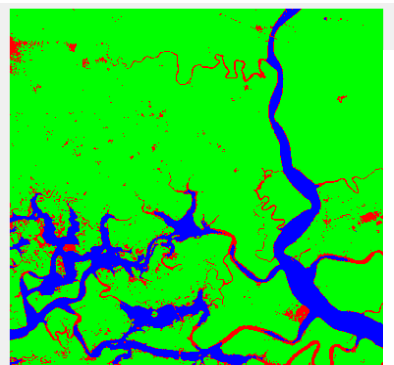

(c)

Bare Land

Water

Vegetation

Fig 8: (a) Testing image 2 (b) NDVI and NDWI classification (b) ANFIS model classification

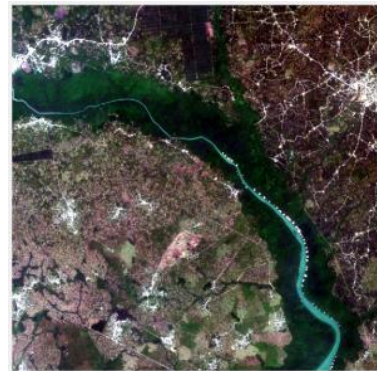

(a)

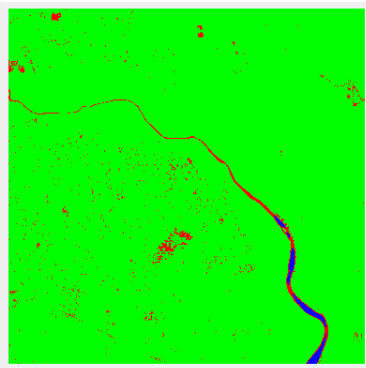

(b)

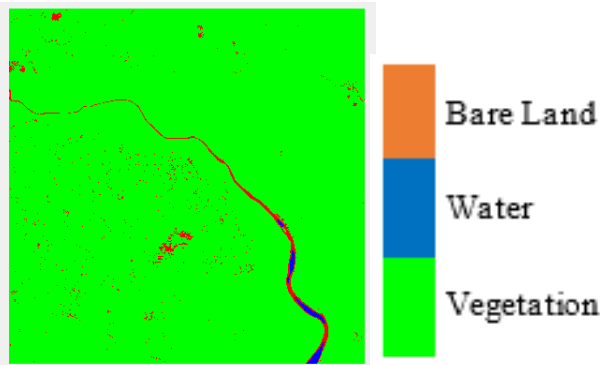

(c)

Fig 9: (a) Testing image 3 (b) NDVI and NDWI classification (b) ANFIS model classification

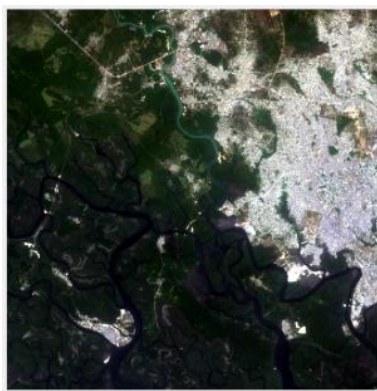

(a)

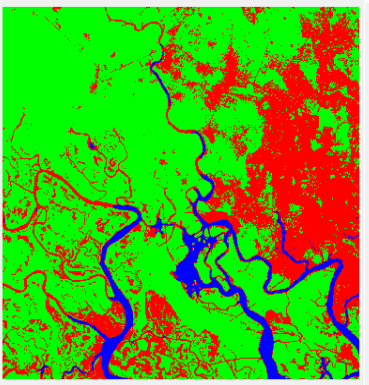

(b)

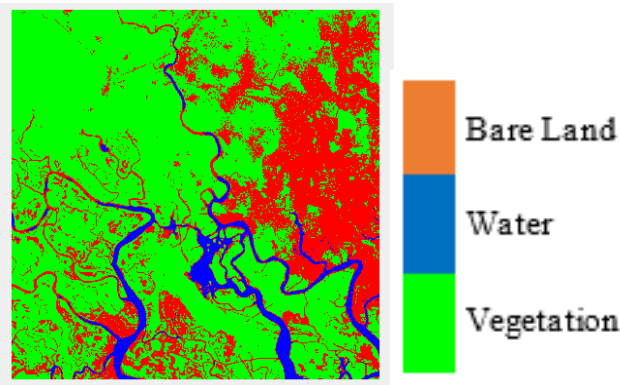

(c)

Fig 10: (a) Testing image 4 (b) NDVI and NDWI classification (b) ANFIS model classification

Table 3: Percentage coverage Area and accuracy for sample testing images

\begin{tabular}{|c|c|c|c|c|c|}
\hline \multirow{2}{*}{$\begin{array}{c}\text { Sample } \\
\text { Images }\end{array}$} & $\begin{array}{c}\text { Earth } \\
\text { features }\end{array}$ & $\begin{array}{c}\text { NDVI } \\
\text { and } \\
\text { NDWI }\end{array}$ & ANFIS & Accuracy & \multirow{2}{*}{ RMSE } \\
\hline \multirow{3}{*}{1} & Bare Land & 16.4384 & 15.8591 & 98.6647 & \\
\cline { 2 - 5 } & Water & 0.0332 & 0.1607 & 99.8473 & \multirow{2}{*}{0.0385} \\
\cline { 2 - 5 } & Vegetation & 83.5284 & 83.9802 & 98.8166 & \\
\hline \multirow{3}{*}{2} & Bare Land & 6.7597 & 6.3309 & 99.2785 & \multirow{2}{*}{0.0283} \\
\cline { 2 - 5 } & Water & 11.2531 & 11.3564 & 99.7377 & \\
\cline { 2 - 5 } & Vegetation & 81.9872 & 82.3127 & 99.5399 & \\
\hline \multirow{3}{*}{3} & Bare Land & 1.8289 & 1.6384 & 99.5739 & \multirow{2}{*}{0.0218} \\
\cline { 2 - 5 } & Water & 0.3998 & 0.2887 & 99.8867 & \multirow{2}{*}{0.0418} \\
\cline { 2 - 5 } & Vegetation & 97.7714 & 98.0729 & 99.6872 & \\
\hline 4 & Bare Land & 30.3330 & 29.1923 & 98.4310 & \\
\hline
\end{tabular}

\begin{tabular}{|c|c|c|c|c|c|}
\hline \multirow{2}{*}{ Water } & 4.8384 & 5.1477 & 99.5793 & \multirow{2}{*}{} \\
\cline { 2 - 5 } & Vegetation & 64.8286 & 65.6600 & 99.8516 & \\
\hline
\end{tabular}

\section{CONCLUSION}

In this paper, a system that can be used to delineate water bodies, soil and vegetation from satellite imagery was developed using adaptive neuro-fuzzy inference system (ANFIS). Red, Blue and NIR bands from Landsat 8 were used to obtained NDVI and NDWI. The indices data obtained were thereafter used, in addition to observed demarcation thresholds for the considered earth surface features, to train the ANFIS model. The simulation results obtained show that the model was able to classify the features with accuracy level of over $98.66 \%$ and RMSE of less than 0.0506 in all cases.

\section{REFERENCES}

[1] Tri Dev Acharya, Dong Ha Lee, In Tae Yang and Jae Kang Lee "Identification of water bodies in a Landsat 8 OLI Image Using a J48 Decision Tree” 2016. 
[2] Aksoy, E.; Ozsoy, G.; Dirim, M.S. (2009). Soil mapping approach in GIS using LandSat Satellite imagery and DEM data. African Journal of Agriculture Research vol.4 (11), pp. 1295-1302.

[3] Warren, A., S. Batterbury and H. Osbahr, 2001. Soil erosion in the West African Sahel: A review and an application of a local political ecology approach in South West Niger. Global Environ. Change, 11: 79-95.

[4] Bationo, A., A. Hartemink, O. Lungu, M. Naimi, P. Okoth, E. Smaling and L. Thiombiano, 2006. African Soils: Their productivity and profitability of fertilizer use. Background Paper, Africa Fertilizer Summit, June 913, 2006, Abuja, pp: 25.

[5] FAO. 1995. Land and environmental degradation and desertification in Africa. The FAO Corporative Documents Repository. Food and Agriculture Organization, Rome, Italy.

[6] Kalra, N. K., Singh, L., Kachhwah, R. and Joshi, D. C. (2010). Remote sensing and GIS in identification of soil constraints for sustainable development in Bhilwara district, Rajasthan. Journal of the Indian Society of Remote Sensing 38(2): 279-290.

[7] Venkataratnam, L. (1980), Use of remotely sensed data for soil mapping. Photonirvachak 8, 19-26.

[8] Kudrat, M., S.K. Saha \& A.K.Tiwari, (1990), Potential use of IRS LISS II digital data in soil landuse mapping and productivity assessment, Asian Pacific Remote Sensing Journal, 2, pp 73-78.

[9] Karale, R.L., (1992), Remote sensing with IRS-1A in soil studies, development, status and prospects. pp 128143. In, R.L. Karale (ed.), Natural Resources Management- A New Perspective. NNRMS, Bangalore.

[10] Asadi, S. S., Vasantha Rao, B. V. T. and Sekar, S. (2012). Creation of physical characteristics information for Natural Resources Management Using remote sensing and GIS: A Model study. International Journal of Modern Engineering Research 2(2): 226-232.

[11] Gates, D.M. 1970. Physicl and Physiological properties of plants. In: Remote sensing with special reference to Agriculture and Forestry. National Academy of Sciences, Washington, D. C. pp. 224-252.

[12] Gausam, H.W., Escobar, D.E, and E.B. Knipling. 1977. Relation of Peperomia obtusifolia's anomalous leaf reflectance to its leaf anatomy. Photogrammetric Engineering and Remote Sensing. 43:1183-1185.

[13] Williams, D.L. 1991. A comparison of spectral reflectance properties at the needle, branch and canopy level for selected conifer species. Remote Sensing of Environment. 35: 79-93.
[14] Ripple, W.J. 1986. Spectral reflectance relationships to leaf water stress. Photogrammetric Engineering and Remote Sensing. 52: 1669-1675.

[15] Hunt, E.R. Jr. and B.N. Rock. 1989. Detection of changes in leaf water content using near-and middle-infrared reflectances. Remote sensing of Environment. 1: 155-159.

[16] Cohen, W.B. 1991. Response of vegetation indices to changes in three measures of leaf water stress. Photogrammetric Engineering and remote sensing. 57: 195-202.

[17] Chuvieco, E. 1998. El factor temporal en teledetección: evolución fenomenológica y análisis de cambios. Revista de Teledetección, 10: 1-9.

[18] DeFries, R. and J. Townshend, NDVI-Derived Land Cover Classifications at a Global Scale, Int.J.Remote Sens. 15 (1994), pp. 3567-3586.

[19] Garrigues, D. S. Allard and F. Baret, Using First-and Second-Order Variograms for Characterizing Landscape Spatial Structures from Remote Sensing Imagery, Geoscience and Remote Sensing, IEEE Transactions on. 45 (2007), pp. 1823-1834

[20] Jackson RD, Huete AR (1991) Interpreting vegetation indexes. Prev Vet Med 11:185-200

[21] Myneni RB, Hall FG, Sellers PJ, Marshak AL (1995). The interpretation of spectral vegetation indexes. IEEE T Geosci Remote 33:481-486

[22] McFeeters, S.K. The use of the Normalized Difference Water Index (NDWI) in the delineation of open water features. Int. J. Remote Sens. 1996, 17, 1425-1432.

[23] Jang R., "Neuro-Fuzzy Modeling," proceedings of the IEEE, vol. 83, no. 3, 1995.

[24] Hamdan H., Garibaldi M. (2010). Adaptive Neuro-Fuzzy Inference System (ANFIS) in Modelling Breast Cancer Survival. WCCI 2010, IEEE World Congress on Computational Intelligence, pp. 18-23.

[25] Rezaei K., Hosseini R., Mazinani M., "A Fuzzy Inference System for Assessment of the Severity of the peptic ulcers," Computer Science \& Information Technology, DOI: 10.5121/ .2014.4527, pp. 263-271, 2014.

[26] Mohd Salleh, M. N., Talpur, N. and Hussain, K. (2017). Adaptive Neuro-Fuzzy Inference System: Overview, Strengths, Limitations, and Solutions. Tan et al. (Eds.): DMBD, LNCS 10387, pp. 527-535, 2017.DOI: 10.1007/978-3-319-61845-6 52 